Article

\title{
The Phytotoxicity of Microencapsulated Peppermint Oil on Maize (Zea mays L.) Depending on the Type of Growth Substrate and Maize Cultivar
}

\author{
Agnieszka Synowiec $^{1,2, * \mathbb{D}}$, Jan Bocianowski ${ }^{3} \mathbb{D}$ and Agnieszka Krajewska 4 (D) \\ 1 LeStudium Institute for Advanced Studies, 45000 Orléans, France \\ 2 Department of Agroecology and Crop Production, University of Agriculture in Krakow, \\ 31-120 Kraków, Poland \\ 3 Department of Mathematical and Statistical Methods, Poznan University of Life Sciences, \\ 60-637 Poznań, Poland; jan.bocianowski@up.poznan.pl \\ 4 Institute of Natural Products and Cosmetics, Lodz University of Technology, 90-924 Łódź, Poland; \\ agnieszka.krajewska@p.lodz.pl \\ * Correspondence: a.synowiec@urk.edu.pl
}

Received: 6 August 2020; Accepted: 27 August 2020; Published: 2 September 2020

\begin{abstract}
Microencapsulated peppermint (Mentha $\times$ piperita L.) essential oil (MPEO) is a prospective botanical herbicide. A hypothesis was formulated that the type of growth substrate (vermiculite, silty clay loam or sandy loam soil) and the cultivar affect the phytotoxic potential of MPEO on maize (Zea mays L.). The pot experiments assessed the effect of varying doses of MPEO or maltodextrin, a carrier of microcapsules, mixed with the growth substrates, on maize's emergence and early growth. The morphological analyses were supported by the measurements of total phenolics in the second leaf and roots. The MPEO revealed phytotoxic effects on maize in all of the growth substrates already at a low dose $\left(36.0 \mathrm{~g} \mathrm{~m}^{-2}\right)$, displayed by the delays of maize emergence, reduced growth, and biomass accumulation. Maltodextrin also caused significant reductions in biomass of maize roots. In conclusion, maize is susceptible to substrate-applied MPEO, the type of substrate and the cultivar of maize, can modify this effect to a limited extent.
\end{abstract}

Keywords: phenolic compounds; dose-response test; maltodextrin

\section{Introduction}

Recently, essential oils (EOs) have been studied in detail for their allelopathic potential against germination and early growth of weeds. In the future, EOs could be applied as so-called botanical herbicides in organic and sustainable food production systems [1,2]. According to research results, EOs rich in monooxygenated monoterpenes, as the leading group of compounds, could be responsible for their allelopathic effects [3]. The main advantage of EOs, over synthetic herbicides, is that they have different modes of actions $[4,5]$ and are readily biodegradable in the environment $[6,7]$.

One of the prospective EOs for weed control is peppermint (Mentha $\times$ piperita L.) EO [8]. The main compounds of the peppermint $\mathrm{EO}$ are menthol and menthone, both monooxygenated monoterpenes, constituting together $45-80 \%$ of the oil [3]. Peppermint EO is one of the most popular EOs, broadly available on the world market. It is steam distilled from the leaves of plants cultivated in Europe, the Americas, and Asia [8,9]. Peppermint EO has multi-uses, e.g., in cosmetic, food, and pharmaceutical industries [10]. Moreover, peppermint EO has a relatively low price compared to other EOs due to its widespread cultivation and application and a high EO content in leaves, in a range of $1.5-2.7 \%[11,12]$.

As a potential botanical herbicide, peppermint EO displays significant allelopathic effects by inhibiting germination and early growth of various weed species [8]. This property could be used in 
the future by applying this oil as a pre-emergence weed control agent. However, to apply it effectively and without loss of oil, peppermint EO should be microencapsulated or nanoencapsulated [13]. In both methods, the liquid micro- or nano-drop of EO is surrounded by different types of solid carriers, ensuring precise application, and reducing evaporation of the EO [13]. Encapsulation also extends the biological activity of the EO, by its slow release [8]. One of the common carriers of microencapsulated EOs is maltodextrin, a polysaccharide with high solubility in water and low viscosity $[14,15]$. Our previous field and pot experiments showed that maltodextrin at high dose $\left(200 \mathrm{~g} \mathrm{~m}^{-2}\right)$ poses a phytotoxic effect on crops, and is allelopathic to weeds $[7,16]$.

Allelopathic effect of the peppermint $E O$ was also verified in a few earlier experiments. For example, the microencapsulated peppermint EO (MPEO) mixed with peat and sand, at a dose $200 \mathrm{~g} \mathrm{~m}^{-2}$, significantly inhibited initial growth of two weeds-lambs quarters (Chenopodium album L.) and barnyard grass (Echinochloa crus-galli (L.) P.Beauv.), but also maize (Zea mays L. 'Wilga') [16]. In another experiment, spraying the peppermint EO, as an oil-in-water emulsion, caused severe necroses on the leaves, reduced biomass, and induced metabolic perturbations of maize [17]. Moreover, in the field experiment, peppermint as a fore-crop significantly reduced the growth and performance of succeeding maize [18].

In a previous experiment, we showed that susceptibility of a species to the MPEO could be, to some extent, modified by the type of a growth substrate, i.e., white mustard (Sinapis alba L. 'Zlata') was more tolerant to the presence of MPEO in the clayey soil than in the vermiculite [19], which is a hydrous phyllosilicate mineral, chemically and biologically inert [20]. The mustard growth impairment in vermiculite was visible at a dose of $73.0 \mathrm{~g} \mathrm{~m}^{-2}$, whereas in the soil-at $108.0 \mathrm{~g} \mathrm{~m}^{-2}$ of MPEO. In the presence of vermiculate and the MPEO mustard was higher and had more hydrated tissues, as compared to the mustard in the clayey soil with the MPEO [19].

This experiment aimed to analyze the response of maize (Zea mays L.) to different doses of (i) microencapsulated peppermint oil (MPEO) and (ii) maltodextrin, depending on the type of growth substrate and the cultivar of maize. We compared the phytotoxicity of both the MPEO and maltodextrin in vermiculite, a neutral growth substrate, and the top layers of two agricultural soils, commonly found in the region, where the experiment was performed. We make a hypothesis that a type of growth substrate, but also the maize cultivar, modify the phytotoxicity of the MPEO and maltodextrin to maize.

\section{Materials and Methods}

\subsection{Characteristics of Microencapsulated Peppermint Essential Oil}

Microencapsulated peppermint essential oil (MPEO) and maltodextrin, used in this experiment, were purchased in 2017 from the commercial producer (Hoffmann Aroma, Zamysłowo, Poland). The MPEO was obtained by the method of a dry spraying. The carrier for the EO was maltodextrin with a small addition (4.5\%) of gum Arabic E414.

The analyses of the MPEO were performed in the laboratory of the Institute of Natural Products and Cosmetics, Lodz University of Technology. The content of peppermint EO in the microcapsules was measured three times by the hydrodistillation method (10 $\mathrm{g}$ of microcapsules and $100 \mathrm{~mL}$ of water) for $2 \mathrm{~h}$, using a Clevenger-type apparatus. The volume of the separated EO was multiplied by the specific density of the microcapsules, which was determined by the pycnometer method. Essential oil was analysed by gas chromatography coupled with mass spectrometry (GC-FID-MS), using a Trace GC Ultra gas chromatograph coupled with DSQ II mass spectrometer (Thermo Electron Corporation, Waltham, MA, USA). The operating conditions were as follows: non-polar capillary column Rtx-1ms $\left(60 \mathrm{~m} \times 0.25 \mathrm{~mm}, 0.25 \mathrm{~m}\right.$ film thickness), programmed temperature: $50(3 \mathrm{~min})-300^{\circ} \mathrm{C}, 4^{\circ} \mathrm{C} / \mathrm{min}$. injector (SSL) temperature $280{ }^{\circ} \mathrm{C}$, detector (FID) temperature $300^{\circ} \mathrm{C}$, transfer line temperature $250{ }^{\circ} \mathrm{C}$, carrier gas-helium, flow with constant pressure $200 \mathrm{kPa}$, split ratio 1:20. The mass spectrometer parameters: ion source temperature $200^{\circ} \mathrm{C}$, ionization energy $70 \mathrm{eV}$ (EI), scan mode: full scan, mass range 33-420. The percentages of constituents were computed from the GC peak area without using a correction factor. 
Identification of the components was based on a comparison of their mass spectra and linear retention indices (RI, non-polar column), determined with reference to a series of $n$-alkanes C8-C24, by compared to those in Adams [21] as well as in computer libraries: NIST 2011, and MassFinder 4.1.

\subsection{Description of the Pot Experiments}

Two dose-response pot experiments were set up in the 2018/2019 season in the Pôle Universitaire greenhouse in Chartres (France). The photoperiod was 14/10, and the temperature was in a range of $5-15{ }^{\circ} \mathrm{C}$ at night and $20-30{ }^{\circ} \mathrm{C}$ during the day. The bottom of each pot $(1 \mathrm{~L}$ vol. $)$ was lined with a standard filter paper layer to prevent losses of substrates and the MPEO. The tested species was maize (Zea mays L.), four cultivars i.e., single cross hybrids: 'Agrojanus' and 'Konfluens,' and triple cross hybrids: 'KWS Stabil' and 'Severno' (all provided by the KWS France). Before the pot experiments, maize's germination was checked, and it was equal to $100 \%$ of germinating seeds per cultivar.

Two pot experiments were set up between September 2018 and May 2019 in a randomized design with four replications. A total of 432 square, black pots of $1 \mathrm{~L}$ volume were filled with one of three different growth substrates at equal doses:

(1) Vermiculite (GRANUTEC ${ }^{\circledR}$ E. www.cmmp.fr). The medium and small-sized vermiculite, $1-3 \mathrm{~mm}$ and 3-6 mm, respectively, were mixed in a proportion of 1:1 $(v / v)$;

(2) Soil 1, collected from a conventional field with winter wheat at La Boissière-École $\left(48^{\circ} 69^{\prime} 29.11^{\prime \prime} \mathrm{N}\right.$, $\left.1^{\circ} 64^{\prime} 84.74^{\prime \prime} \mathrm{E}\right)$;

(3) Soil 2, collected from the organic field with winter wheat at the Agricultural College de Chartres-La Saussaye $\left(48^{\circ} 40^{\prime} 41.3^{\prime \prime}\right.$ N, $1^{\circ} 55^{\prime} 58.71^{\prime \prime}$ E).

Both of the soils were collected in Autumn 2018, from the top-layers of soils (ca. 20-cm-deep). The soils were kept outside in the boxes until Spring 2019. Before the experiment, soils were air-dried and sieved through a $2-\mathrm{cm}$ mesh, to remove all the impurifications. The granulometric and chemical analyses of soils were performed in the Laboratoire d'Analyses Chambre d'Agriculture Loiret in Orleans, France, and are presented in Table 1. Based on the particle sizes, the soil 1 was classified as sandy loam, whereas the soil 2 as silty clay loam.

Table 1. Texture and chemical composition of both soils.

\begin{tabular}{cccccccccc}
\hline & Sand & Clay & Silt & $\mathbf{C}_{\text {org }}$ & $\mathbf{P}_{\mathbf{2}} \mathbf{O}_{5}$ & $\mathbf{K}_{\mathbf{2}} \mathbf{O}$ & $\mathbf{M g O}$ & $\mathbf{N}_{\text {total }}$ & $\mathbf{p H}$ \\
\cline { 2 - 9 } & $\mathbf{( \% )}$ & $\mathbf{( \% )}$ & $\mathbf{( \% )}$ & $\mathbf{( \mathbf { g ~ k g } ^ { - 1 } )}$ & $\mathbf{( \mathbf { m g ~ k g } ^ { - 1 } )}$ & $\mathbf{( \mathbf { m g ~ k g } ^ { - 1 } )}$ & $\mathbf{( \mathbf { m g ~ k g } ^ { - \mathbf { 1 } } )}$ & $\mathbf{( \mathbf { g ~ k g } ^ { - 1 } )}$ & \\
\hline Soil 1 & 56 & 8.9 & 35.1 & 11.8 & 82 & 193 & 99 & 1.09 & 6.57 \\
Soil 2 & 5.2 & 31.3 & 63.5 & 12.7 & 86 & 270 & 117 & 1.38 & 7.93 \\
\hline
\end{tabular}

In the experiment I, different doses of MPEO: 0 (control); $0.44 ; 0.66 ; 0.88 ; 1.31$ and 1.76 g per pot (equal to 36; 55; 73; 108 and $145 \mathrm{~g} \mathrm{~m}^{-2}$ ), were mixed with the growth substrates in the pots up to 3-cm-deep. On the same day, one kernel of maize per pot was seeded at a ca. $2.0 \mathrm{~cm}$ depth.

In the experiment II, different doses of maltodextrin carrier: 0 (control); 0.88 and $1.76 \mathrm{~g}$ per pot (equal to 73 and $145 \mathrm{~g} \mathrm{~m}^{-2}$ ) were added to the pots and mixed with the substrates. Also, one kernel of maize per pot was seeded.

Maize was watered with tap water every $2-3$ days. No fertilization was applied, to prevent a potential interaction between fertilizer and the MPEO.

\subsection{Maize Measurements}

The emergence time of maize was recorded. Both experiments were terminated when each of the plants reached two leaves' growth stage (BBCH 12). In that stage, plants were removed from the pots, cut at the stem's base. Roots were carefully washed under tap water and gently dried using paper tissues. The length of shoots (up to the tip of the youngest leaf) and roots were measured with a ruler. 
The second leaf was cut at the base of the leaf blade, gently unfoiled and photographed to measure its area (by ImageJ ver. 1.52. imagej.nih.gov/ij). Shoots of maize were dried in the oven at $105^{\circ} \mathrm{C}$ for $24 \mathrm{~h}$, and after that their dry weight was weighed, using laboratory balance (with $0.01 \mathrm{~g}$ accuracy). Roots of maize and the second leaf were packed separately and freeze-dried (Alpha 1-2 LDplus, M. Christ $\mathrm{GmbH}$ ). After that their dry weight was weighed, using laboratory balance (with $0.001 \mathrm{~g}$ accuracy). The second leaf's specific weight was calculated, based on its area and dry weight [22].

Methanolic extracts (50\%) of lyophilized second leaves and maize roots, separately, were prepared using ultrasound-assisted extraction for $60 \mathrm{~min}$ (Prolab Instruments $\mathrm{GmbH}$, Kanton Reinach, Switzerland). The Folin-Ciocalteu assay of total phenolic content with absorbance readings at $630 \mathrm{~nm}$ was taken after incubation and expressed in gallic acid as a reference phenolic [23], in two technical repetitions.

\subsection{Statistical Analysis}

The normality of the parameters (shoot length, root length, shoot dry weight, root dry weight, leaf area, specific leaf weight, phenolics in the second leaf, and roots) was tested using Shapiro-Wilk's test [24]. Next, a multivariate analysis of variance (MANOVA) was performed.

The relationships between observed parameters were assessed based on Pearson's correlation for a particular substrate independently. Relationships of observed parameters were presented as heatmaps. A three-way analysis of variance (ANOVA) was carried out to determine the effects of substrates, doses, and cultivar and all interactions on the variability of the parameters mentioned above. The mean values and standard deviations were calculated. Fisher's least significant differences (LSDs) were calculated for individual parameters, and on this basis, homogeneous groups were determined.

Data were also analyzed using multivariate methods. The canonical variate analysis was applied to present a multi-parameter assessment of similarity of combinations of levels of tested factors (substrates, doses, and cultivars) in a lower number of dimensions with the least possible loss of information $[25,26]$. The canonical analysis makes it possible to illustrate the variation in combinations in terms of all observed parameters in the graphic form. Mahalanobis distance [27] was suggested as a measure of "poly parameter" combinations dissimilarity [28]; significance was verified employing critical value D $\alpha$ called "the least significant distance" [29].

The ED50 values, i.e., the values causing 50\% reduction in a measured parameter, were calculated using the 'drc' package [30] in the RStudio: Integrated Development for R (ver. 1.2.5033, PBC, Boston, MA, USA) software. The relationships between the ED50 values of observed parameters were assessed based on Pearson's correlation. The differences among analyzed combinations of growth substrates and cultivars were verified by the cluster analysis using the nearest neighbor method and Euclidean distances.

For the control experiment with maltodextrin only, a three-way ANOVA was carried out. It aimed to determine the effects of substrates, doses, and cultivar and all interactions on the variability of shoot length, root length, shoot dry weight, root dry weight, leaf area, specific leaf weight, phenolics content in the second leaves and roots of maize. The mean values and standard deviations of the observed parameters were calculated. Fisher's least significant differences (LSDs) were calculated for individual parameters, and on this basis, homogeneous groups were determined.

The statistical analyses were conducted using the GenStat 18th edition statistical software package (VSN International).

\section{Results}

\subsection{Chemical Composition of Peppermint Oil in the Microcapsules}

Based on the hydrodistillation analysis, the average content of peppermint EO in the microcapsules was $0.96 \mathrm{~mL}$ per $10 \mathrm{~g}$ of microcapsules, equal to $9.6 \%$ of $\mathrm{EO}$ in the microcapsules (v/w). The chemical composition of the analyzed peppermint EO was, in general, typical for this oil, with the main 
compounds being menthol and menthone, constituting together $\sim 80 \%$ of the oil. However, the oil contained higher amounts of menthol and lacked limonene oxide compared to the European Pharmacopoeia [31] (Table 2).

Table 2. Chemical composition of peppermint oil encapsulated in the maltodextrin microcapsules.

\begin{tabular}{|c|c|c|c|c|c|}
\hline Compound & $\mathrm{EP}[\%]^{1}$ & RI Lit ${ }^{2}$ & RI $\operatorname{Exp}^{3}$ & $\mathrm{RT}^{4}$ & Average [\%] \\
\hline$\alpha$-Pienen & & 934 & 930 & 11.79 & 0.4 \\
\hline Sabinene & & 970 & & 13.25 & 0.1 \\
\hline$\beta$-Pinene & & 974 & 969 & 13.34 & 0.6 \\
\hline 1.8-Cineol & $3.5-14.0$ & 1024 & 1017 & 15.38 & 4.2 \\
\hline Limonene & & 1025 & 1021 & 15.48 & 0.6 \\
\hline Limonene Oxide & $0.1-5.0$ & & & & - \\
\hline Menthone & $14.0-32.0$ & 1139 & 1134 & 20.14 & 20.6 \\
\hline Isomenthone & $1.5-10.0$ & 1046 & 1142 & 20.40 & 3.7 \\
\hline Menthofuran & $0.1-0.9$ & 1050 & & & $t^{5}$ \\
\hline Neomenthol & & 1155 & 1150 & 20.71 & 2.5 \\
\hline Menthol & $30.0-55.0$ & 1163 & 1166 & 21.40 & 60.1 \\
\hline Neoisomenthol & & 1171 & 1170 & 21.52 & 0.4 \\
\hline Isomenthol & & 1176 & 1176 & 21.73 & 0.2 \\
\hline Pulegone & $<4.0$ & 1218 & 1215 & 23.34 & 0.2 \\
\hline Piperitone & & 1232 & 1233 & 23.81 & 0.2 \\
\hline Menthyl Acetate & & 1280 & 1275 & 25.56 & 4.0 \\
\hline Bicycloelemene & & 1338 & 1328 & 27.51 & 0.1 \\
\hline$\beta$-Bourbonene & & 1386 & 1378 & 29.27 & 0.1 \\
\hline (E)- $\beta$-Caryophyllene & & 1421 & 1410 & 30.40 & 0.4 \\
\hline$\varepsilon$-Muurolene & & 1455 & 1445 & 31.48 & 0.1 \\
\hline \multirow[t]{2}{*}{ Caryophyllene Oxide } & & 1573 & 1568 & 35.40 & 0.9 \\
\hline & & & & Total identified & 99.33 \\
\hline
\end{tabular}

${ }^{1}$ EP-European Pharmacopoeia [27]; ${ }^{2}$ RI lit—standard retention index; ${ }^{3}$ RI exp.—experimental retention index;

${ }^{4} \mathrm{RT}$-retention time; ${ }^{5} \mathrm{t}$ - trace $<0.05 \%$.

\subsection{The Effect of MPEO on Emergence of Maize}

The time of maize emergence was assessed for each maize plant separately, and the delays of their emergence were calculated with the respective controls (each of the substrates without addition of the MPEO), in which the plants emerged first. The results showed that the delays of emergence in the vermiculite mixed with the MPEO were the highest. On the contrary, maize's fastest emergence was noted in the pots with the MPEO plus clayey soil (soil 2) (Figure 1). Moreover, in the clayey soil pots, all of the maize cultivars' emergence was uniform up to a dose of $55 \mathrm{~g} \mathrm{~m}^{-2}$. On the other hand, in vermiculite at the highest dose of MPEO, three cultivars emerged, except 'Severno.' However, delays in their emergence were substantial, in a range of 7-10 days later, compared to the control pots. In both soils 1 and 2, at the highest doses of MPEO, maize's emergence was either a few days later (2-9) from the control or plants did not emerge at all. Among the tested maize cultivars, the most prolonged delays in emergence were observed for 'KWS Stabil' growing in vermiculite mixed with the MPEO (9 to 12 days) (Figure 1 ).

\subsection{The Effect of Substrates and Doses of MPEO on Maize Growth}

The results of MANOVA indicated that the doses of MPEO (Wilk's $\lambda=0.0927 ; F_{5 ; 216}=16.58$; $p<0.0001$ ), the growth substrates (Wilk's $\lambda=0.0828 ; F_{2 ; 216}=64.64 ; p<0.0001$ ), the cultivars (Wilk's $\left.\lambda=0.6901 ; F_{3 ; 216}=3.45 ; p<0.0001\right)$, and interactions:, dose $\times$ substrate $\left(\right.$ Wilk's $\lambda=0.1177 ; F_{10 ; 216}=6.69$; $p<0.0001$ ), substrate $\times$ cultivar (Wilk's $\lambda=0.4977 ; F_{6 ; 216}=3.28 ; p<0.0001$ ), dose $\times$ cultivar (Wilk's $\left.\lambda=0.3312 ; F_{15 ; 216}=2.10 ; p<0.0001\right)$ and dose $\times$ substrate $\times$ cultivar $\left(\right.$ Wilk's $\lambda=0.1275 ; F_{30 ; 216}=2.08$; $p<0.0001$ ) were significantly different with regard to all of the eight quantitative parameters. 


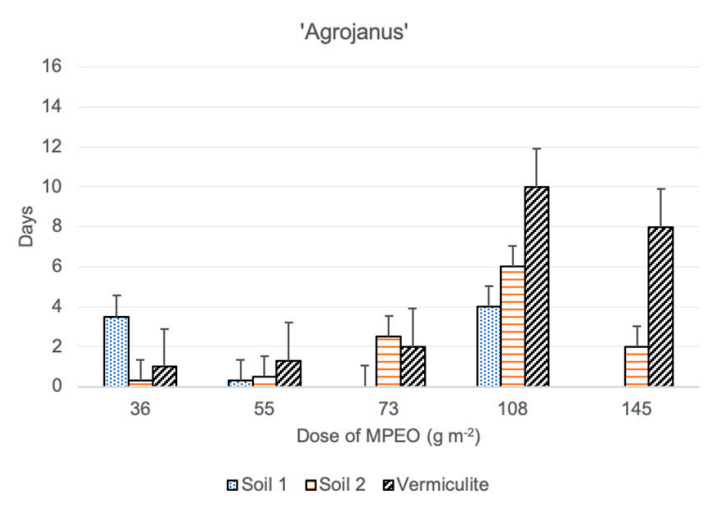

(a)

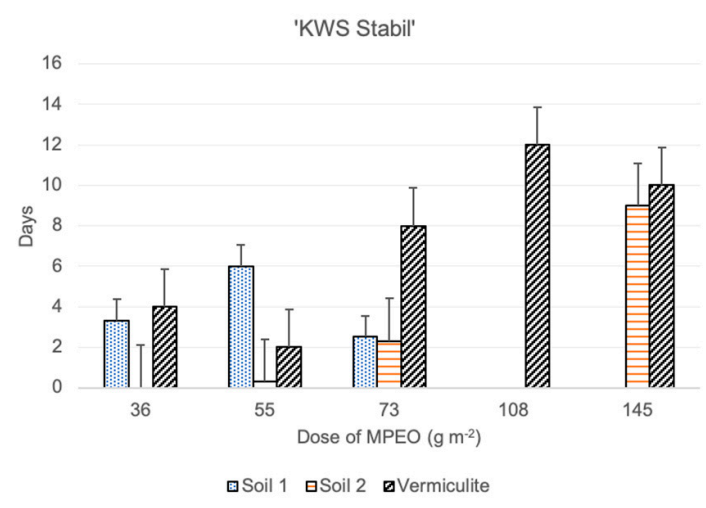

(c)

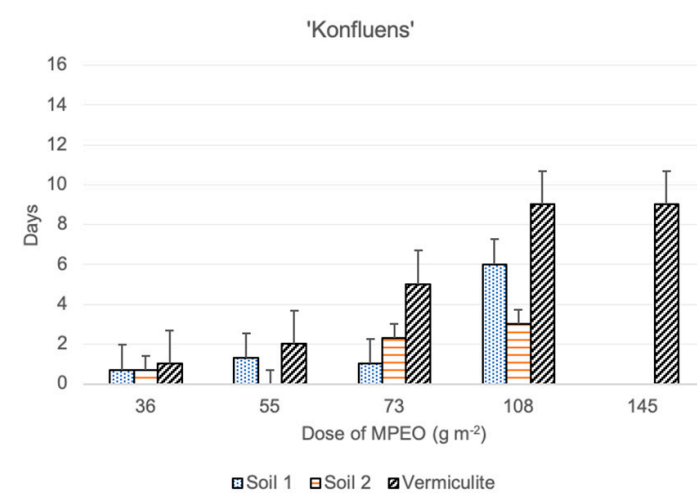

(b)

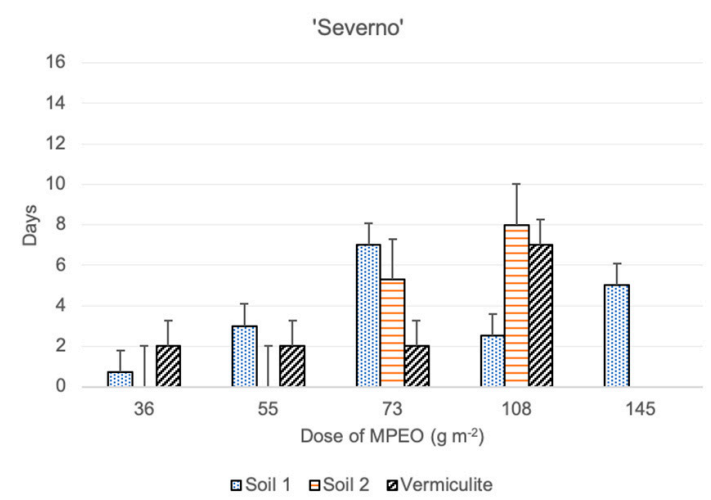

(d)

Figure 1. The effect of microencapsulated peppermint oil (MPEO) on delay of maize emergence (in days) depending on the substrate (mean values + standard error); single cross hybrids: (a) 'Agrojanus' and (b) 'Konfluens,' and triple cross hybrids: (c) 'KWS Stabil' and (d) 'Severno'.

The highest values of Pearson's correlation were observed for maize growing in the sandy soil 1 (Figure 2b), and the lowest-in vermiculite (Figure 2a). For maize growing in the vermiculite, positive correlations were observed for the pairs of parameters: shoot length, root length, shoot dry weight, dry root weight, and second leaf area (Table S1, Figure 2a). Additionally, a positive correlation was observed for phenolics content in the second leaf and roots (0.704) whereas negative correlations for specific leaf weight and phenolics in roots (-0.209) (Table S1, Figure 2a). For maize in the sandy soil 1 , the analysis indicated statistically significant and positive correlations between all the measured parameters (Table S2, Figure 2b). In the clayey soil 2, significantly positive correlations were observed for some of the pairs of parameters, except for the correlation of phenolics in roots with maize shoot length $(r=0.189)$, root length $(0.161)$, shoot dry weight $(0.037)$, root dry weight $(0.000)$ and leaf area (0.078) (Table S2, Figure 2b).

The results of ANOVA showed that the main effects of substrate, dose, and cultivar were significant for all the measured parameters (Table S3). Substrate $\times$ dose interaction was significant for the majority of parameters except for the shoot length. Substrate $\times$ cultivar interaction significantly determined most of the parameters except for the phenolics in roots (Table S3). Dose $\times$ cultivar and substrate $\times$ dose $\times$ cultivar interactions were statistically significant for shoot dry weight, root dry weight, leaf area, and the content of phenolics in the second leaf and roots. Additionally, substrate $\times$ dose $\times$ cultivar interaction was significant for the shoot length (Table S3).

All of the maize cultivars followed the dose-response pattern in response to the increasing doses of MPEO, which was reflected by decreasing lengths of shoots and roots (Tables S4 and S5). The dry weight of plants, especially roots, was a parameter that was mostly affected by the presence of MPEO. 
A significant drop of root dry weight for all of the maize cultivars growing in each of the substrates was noted already at the lowest dose of MPEO (dose 1 equal to $36 \mathrm{~g} \mathrm{~m}^{-2}$ ) (Table S6). A resulting drop of dry shoot weight depended on the type of a substrate and was observed at a dose 1 of MPEO in the sandy soil 1 and a dose $2\left(55 \mathrm{~g} \mathrm{~m}^{-2}\right)$ in the clayey soil 2 or vermiculite (Table S7). Interestingly, the specific second leaf weight (SLW) was similar for controls of different cultivars grown in the same soil substrate type.

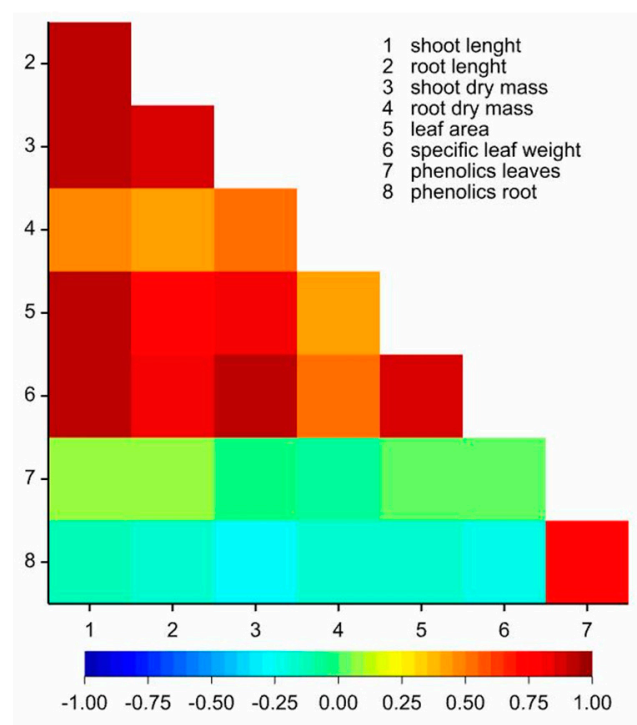

(a)

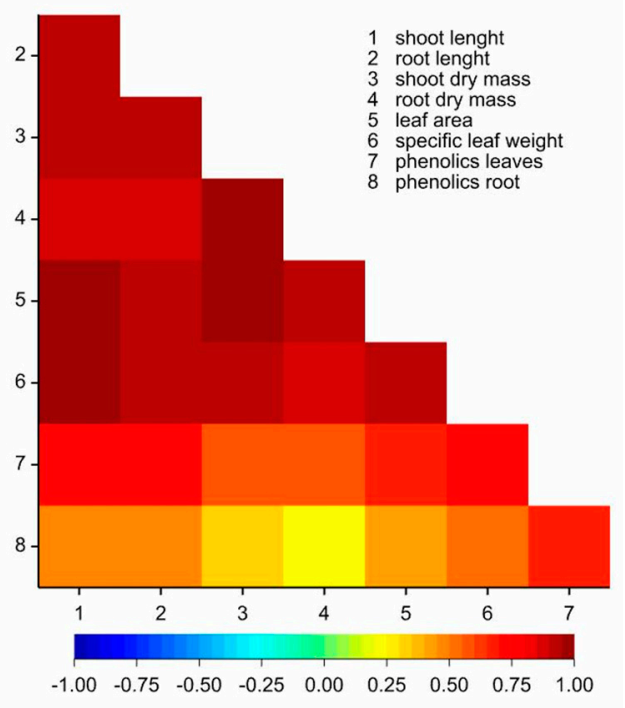

(b)

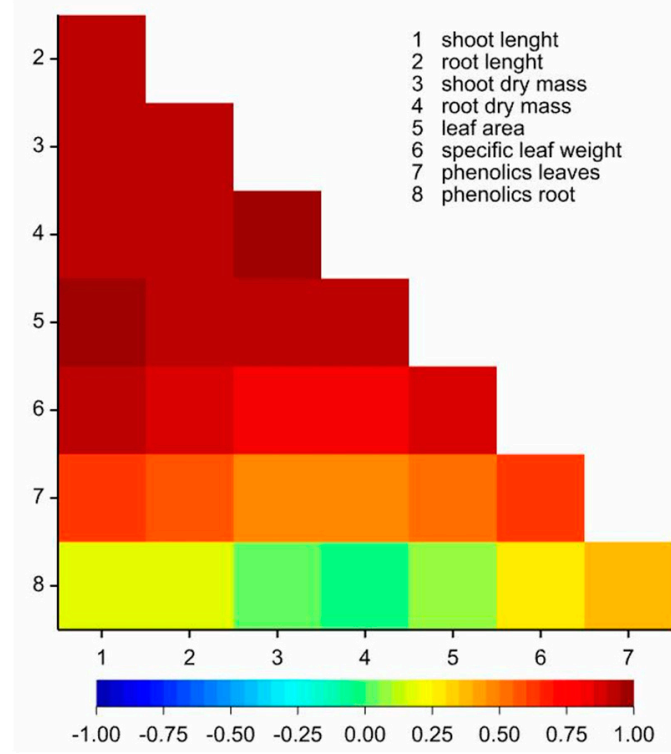

(c)

Figure 2. Heatmap for linear Pearson' correlation coefficients between observed parameters in (a) vermiculite $\left(r_{0.05}=0.201\right)$; (b) soil $1\left(r_{0.05}=0.201\right)$; and (c) soil $2\left(r_{0.05}=0.201\right)$.

In contrast, in vermiculite, the SLWs of controls were already significantly different. The most pronounced drop of the SLW, as the result of the MPEO treatments, was observed for 'KWS Stabil.' Also, 'Agrojanus' growing in the soil 1 amended with the MPEO displayed a significant drop of the SLW already at the lowest dose of the MPEO, by $43 \%$ compared to control (Table S8).

The total content of phenolic compounds in the second leaf and maize roots was variable for both types of substrate and cultivars (Tables S9 and S10). On average, maize roots treated with the MPEO 
contained much higher amounts of phenolic compounds than the second leaf. However, in the soils 1 and 2, phenolics' content in the second leaf was $43 \%$ and $25 \%$ lower, compared to vermiculite. On the contrary, the total content of phenolic compounds in maize roots from the two soils was several times higher than in vermiculite. There was no apparent dose-response effect of MPEO on the total content of phenolic compounds in both the second leaf and maize roots. In some of the combinations, however, increased amounts of phenolic compounds in the second leaf were observed in cultivars of maize growing in vermiculite at higher doses of MPEO, i.e., 'Agrojanus' (Table S9).

The multivariate canonical analysis was performed for the 72 combinations of the factors and eight quantitative parameters, to combine the tested factors (substrates, doses of MPEO, and cultivars) (Figure 3). In Figure 3, the point for particular combinations' coordinates is the values for the first and second canonical variables, respectively. The primary two canonical variables accounted for $75.90 \%$ of the total multivariate variability between the individual combinations (Table S11, Figure 3). The most significant, positive, and linear relationship between the first canonical variable was found for the specific leaf weight (Table S11). The first canonical variable was negatively correlated with the shoot length, shoot dry weight, root dry weight, leaf area, and total phenolics content in roots (Table S11). The second canonical variable was significantly positively correlated with the shoot length, root length, shoot dry weight, root dry weight, leaf area, specific leaf weight, and phenolics content in the second leaf (Table S11). The most significant variation in terms of all of the eight parameters jointly, measured as the Mahalanobis distances, was found for 'KWS Stabil'/soil 2/dose $2\left(55 \mathrm{~g} \mathrm{~m}^{-2}\right)$ and 'Severno'/vermiculite/dose 0. The Mahalanobis distance between them amounted to 11.861. The highest similarity (equal to 0.000) was found for the combinations, including each of the tested cultivars growing in each substrate at the two highest doses of MPEO (Figure 3).

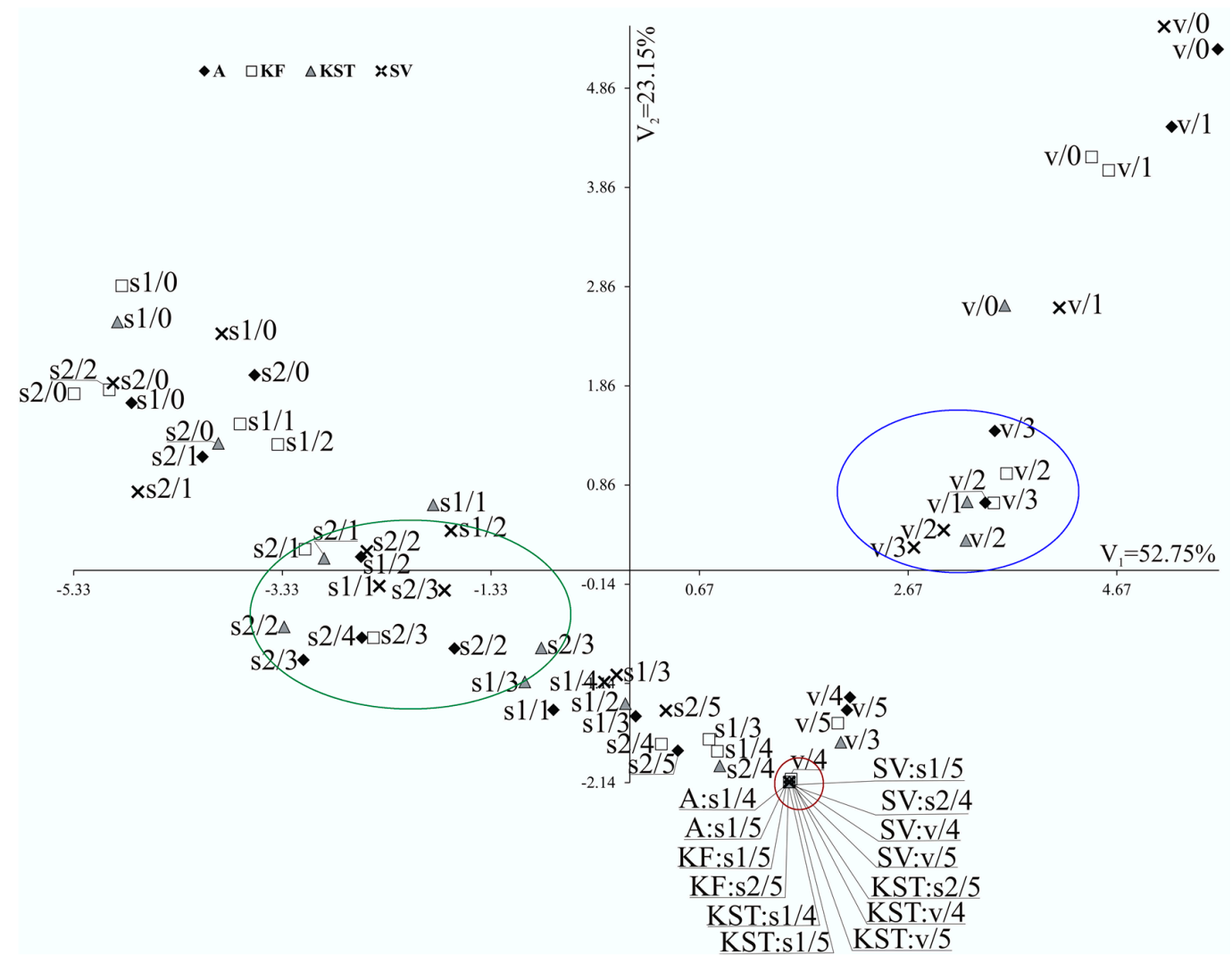

Figure 3. Distribution of 72 combinations of levels of tested factors (doses, growth substrates and cultivars) in the space of the first two canonical variables. Combination $x / y$ denotes $x-$ growth substrate and y-dose; v-vermiculite, s1-soil 1, s2—soil 2; doses 0, 1, 2, 3, 4 and 5 denote 0, 36, 55, 73, 108 and $145 \mathrm{~g} \mathrm{~m}^{-2}$ of MPEO, respectively. 
The canonical analysis (Figure 3) clearly showed that maize's response to the effect of MPEO depends on a type of growth substrate, which plays a more significant role than the maize cultivar. Maize growing in vermiculite at doses 2 and 3 (blue circle) performed better than maize growing in the soil 1 and soil 2 in the presence of the same doses of MPEO (green circle). On the contrary, at the two highest doses of MPEO ( 4 and 5), none of the growth substrates could diminish the phytotoxic effects of MPEO (red circle).

Based on the ED50 values, calculated for the biometrical parameters, it was shown that the most susceptible to the MPEO treatments, regardless of the substrate, was 'KWS Stabil,' as it had the lowest ED50 values (Table 3).

Table 3. Effective doses causing $50 \%$ of inhibition (ED50) values ( \pm standard error) ${ }^{1}$ for the maize cultivars growing in the three different growth substrates amended with five doses of microencapsulated peppermint oil.

\begin{tabular}{|c|c|c|c|c|c|c|}
\hline \multirow{2}{*}{ Cultivar $^{2}$} & \multicolumn{2}{|c|}{ Length (cm) } & \multicolumn{2}{|c|}{ Dry Weight (g) } & \multicolumn{2}{|c|}{ Second Leaf } \\
\hline & Shoot & Root & Shoot & Root & $\begin{array}{l}\text { Specific Weigth } \\
\text { (mg) }\end{array}$ & Area $\left(\mathrm{cm}^{2}\right)$ \\
\hline \multicolumn{7}{|c|}{ Vermiculite } \\
\hline A & $80.5 \pm 11.3$ & $85.1 \pm 16.6$ & $55.5 \pm 5.7$ & $60.6 \pm 57.8$ & $90.3 \pm 11.2$ & $60.8 \pm 6.2$ \\
\hline KF & $75.3 \pm 11.1$ & $62.5 \pm 9.3$ & $58.2 \pm 7.0$ & $40.9 \pm 4.5$ & $74.3 \pm 11.6$ & $73.0 \pm 12.8$ \\
\hline KST & $61.2 \pm 5.0$ & $56.8 \pm 4.5$ & $48.6 \pm 10.1$ & $16.5 \pm 60.0$ & $57.5 \pm 11.2$ & $61.7 \pm 6.0$ \\
\hline SV & $63.6 \pm 7.0$ & $79.9 \pm 11.9$ & $45.7 \pm 6.0$ & $35.3 \pm 4.3$ & $69.0 \pm 10.0$ & $48.7 \pm 4.8$ \\
\hline \multicolumn{7}{|c|}{ Soil 1} \\
\hline A & $49.0 \pm 14.13$ & $48.4 \pm 16.60$ & $19.9 \pm 11.90$ & $11.5 \pm 10.46$ & $48.7 \pm 15.87$ & $71.7 \pm 7.46$ \\
\hline $\mathrm{KF}$ & $61.8 \pm 1.81$ & $64.0 \pm 3.51$ & $59.4 \pm 1.82$ & $59.3 \pm 2.94$ & $63.1 \pm 1.80$ & $67.6 \pm 3.45$ \\
\hline KST & $51.2 \pm 6.31$ & $44.9 \pm 4.03$ & $38.7 \pm 3.82$ & $29.9 \pm 4.63$ & $36.8 \pm 5.46$ & $54.5 \pm 7.31$ \\
\hline SV & $72.1 \pm 12.90$ & $67.0 \pm 11.34$ & $41.5 \pm 11.38$ & $45.6 \pm 12.34$ & $57.7 \pm 8.90$ & $74.1 \pm 12.33$ \\
\hline \multicolumn{7}{|c|}{ Soil 2} \\
\hline $\mathrm{A}$ & $86.5 \pm 22.77$ & $75.3 \pm 16.71$ & $57.7 \pm 9.62$ & $64.1 \pm 12.71$ & $95.7 \pm 26.18$ & $111.0 \pm 35.41$ \\
\hline KF & $81.6 \pm 3.46$ & $79.1 \pm 5.41$ & $72.6 \pm 2.01$ & $72.3 \pm 3.85$ & $74.3 \pm 9.15$ & $94.8 \pm 5.49$ \\
\hline KST & $55.4 \pm 7.12$ & $67.2 \pm 8.49$ & $43.2 \pm 8.25$ & $44.5 \pm 8.99$ & $55.2 \pm 8.57$ & $63.1 \pm 8.19$ \\
\hline SV & $82.0 \pm 8.29$ & $78.9 \pm 8.80$ & $63.5 \pm 7.71$ & $58.3 \pm 6.22$ & $66.9 \pm 5.16$ & $84.2 \pm 12.91$ \\
\hline
\end{tabular}

${ }^{1}$ The ED50 values and standard errors were calculated in the 'drc' package in RStudio (ver. 1.2.5033, PBC, Boston, MA, USA); ${ }^{2}$ Cultivar: A-'Agrojanus', KF-'Konfluens', KST-'KWS Stabil', SV-'Severno'.

In the presented dendrogram, as a result of the nearest neighbor grouping based on the ED50 values and using the Euclidean distances method, all of the examined combinations of cultivar and substrate were divided into three groups (Figure 4). This analysis showed again that in the reaction of maize to the substrate-applied MPEO, the type of growth substrate was more critical than the cultivar. The first group comprised of combinations including mainly soil 2 and three cultivars: 'Agrojanus' (A/s2), 'Konfluens' $(\mathrm{KF} / \mathrm{s} 2)$ and 'Severno' (SV/s2), and also 'Agrojanus' growing best on vermiculite amended with MPEO $(\mathrm{A} / \mathrm{v})$. On the other end, there was a group composed of maize growing poorly, mainly 'KWS Stabil' growing in two substrates amended with the MPEO: vermiculite (KST/v) and soil 1 (KST/s1) but also 'Agrojanus' growing more deficient in the soil 1 amended with the MPEO (A/s1) (Figure 4).

To assess the actual effect of maltodextrin only on maize, also a separate, second experiment was performed. In this experiment, maize's performance in the presence of the two highest concentrations of maltodextrin (108 and $145 \mathrm{~g} \mathrm{~m}^{-2}$ ) was compared with maize in pots without the addition of maltodextrin. The three-way ANOVA results revealed that the substrate's main effects were significant for all of the quantitative parameters of maize (Table S12). The maltodextrin dose was also statistically significant for root length and dry weight, and the specific second leaf weight. The cultivars significantly determined root length, specific second leaf weight, and phenolics content in roots of maize (Table S12). A detailed analysis revealed that the maltodextrin affected mainly growth and biomass accumulation in roots of maize (Tables S13 and S14). Specifically, the most susceptible were 'Agrojanus' and 'KWS Stabil' 
growing in the soil 1 . In the soil 1 at the highest dose of maltodextrin $\left(145 \mathrm{~g} \mathrm{~m}^{-2}\right)$, a decrease of dry root weight was by $43 \%$ and $48 \%$ for 'Agrojanus' and 'KWS Stabil,' respectively as compared to the non-treated control (Table S14). Interestingly, for the same combination of soil 1 and maltodextrin, a significant increase of phenolics in the roots was noted for the 'Agrojanus' only by $40 \%$ at the highest dose compared to control (Table S15).

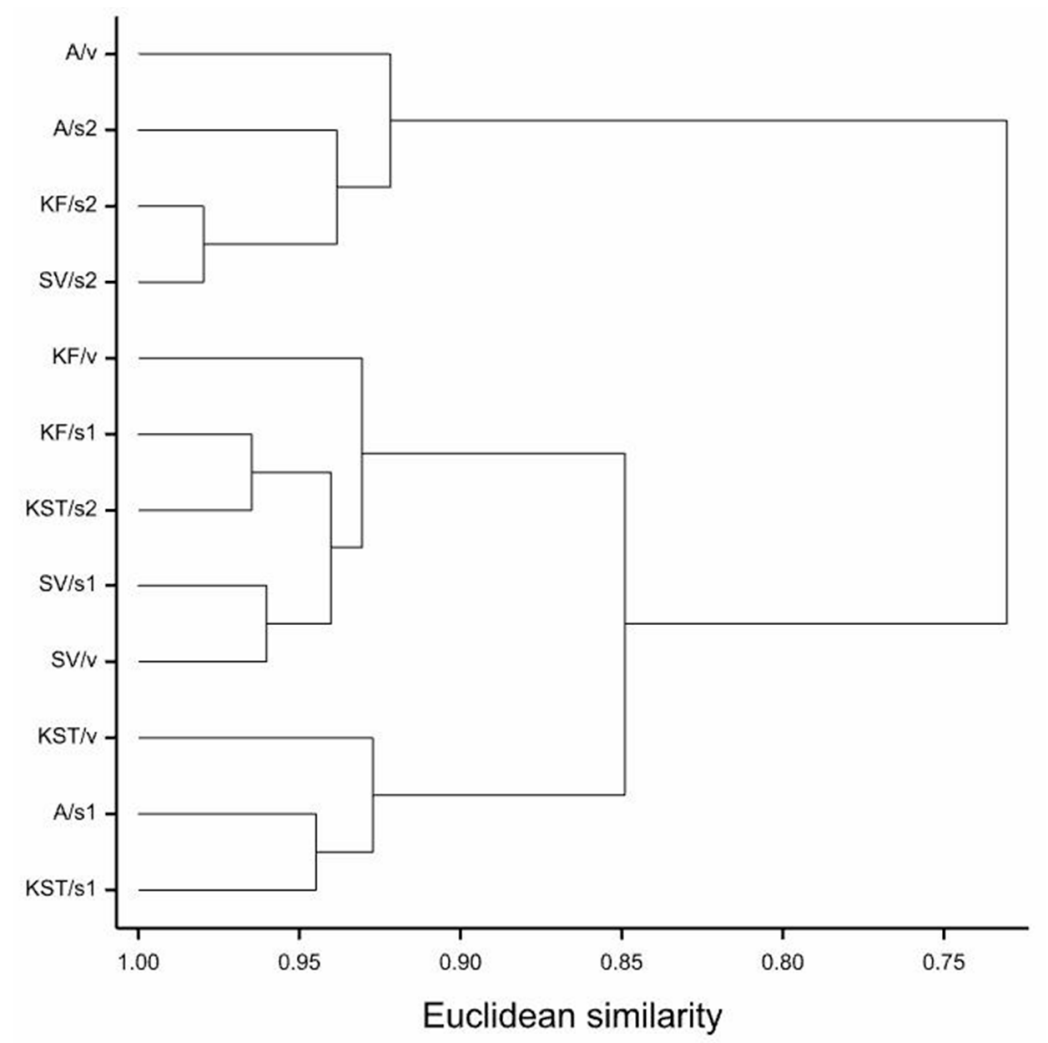

Figure 4. Dendrogram of the nearest neighbor cluster grouping of 12 substrate-by-cultivar combinations (Euclidean distances), calculated on the basis of six morphometrical parameters of maize.

\section{Discussion}

Our results showed that the microencapsulated peppermint oil (MPEO), which is substrate-applied and mixed prior sowing of maize, negatively affects maize's initial growth. This effect depends in order on the dose of MPEO, the type of substrate, and the maize cultivar. The adverse effects include delays in maize emergence, inhibited elongation of roots and shoots, and decreased biomass accumulation. The earlier experiments showed that maize is susceptible to the phytotoxic effect of water preparations containing peppermint essential oil, i.e., water solutions of the oil affect germination of maize seeds and seedlings' growth [3]. When the peppermint oil is foliar sprayed as an oil-in-water emulsion, it causes burns of maize leaves [17,32].

In the present experiment, the inhibiting effect of the substrate applied MPEO toward maize was visible already at maize emergence. Early and uniform emergence of maize is one of the crucial factors that support maize in its competitive efforts toward weeds [33-36] and ensures a high yield of maize [37]. The observed delays of emergence caused by the MPEO negatively affected maize performance also in the later stages of development (the second-leaf stage). Maize susceptibility to the MPEO at the stage of emergence depended, to some extent, on the type of substrate. We observed that maize emerged better in the vermiculite and, to a certain level, also in the silty clay loam soil. Similarly, vermiculite mixed with the MPEO was less phytotoxic to maize at the two leaves' growth stage, especially compared to the sandy soil. Most probably, better sorption capabilities of both vermiculite and clayey soil, i.e., high contents of floatable soil fractions in the clayey soil, played a role in adsorbing 
the EO and alleviating its adverse effects on maize to some extent. Vermiculite is known on an excellent sorption ability, i.e., it can remediate soil from polluting compounds [38]. Vermiculite also has a suitable water holding capacity and, due to the particle structure, maintains a higher temperature of soil $[39,40]$. Both of these characteristics of vermiculite are crucial for the proper development of maize in the first stages of growth [41]. We hypothesize that vermiculite could alleviate the adverse effects of the MPEO on maize by supporting physical conditions of its initial growth. Contrarily to our findings, vermiculite was less supportive of the initial growth of white mustard in the presence of the MPEO than clayey soil [19]. As authors speculate, this difference could result from higher amounts of nutrients in the soil than vermiculite, which promoted buildup of the mustards' biomass [19]. In case of initial growth of maize, the availability of nutrients in the growth substrate could be of lower importance, as the kernel could support them [42].

The phytotoxic effects of the MPEO on maize in the two leaves' growth stage were expressed mostly by reduced root biomass, but also reduced biomass of the aboveground parts. Increased susceptibility of roots towards the MPEO could result from the direct phytotoxic effect of peppermint essential oil, which at higher concentrations can cause even dieback of tissues. Similar effects were observed by Synowiec et al. [3] in the Petri dish experiments, where the radicles of maize seedlings were significantly more affected by the essential oil, compared to coleoptiles.

There was no apparent dose-response effect of the MPEO on the total content of phenolic compounds in both the second leaf and maize roots. However, increased amounts of phenolic compounds in the second leaf were observed in some of the cultivars grown in higher doses of MPEO. The content of phenolics, which are structurally diverse secondary metabolites, increases in the tissues when plants undergo stress $[43,44]$. Their role is to alleviate the stress by scavenging the reactive oxygen species (ROS) directly or through enzymatic reactions [45]. As pointed by Singh et al. [46], the phytotoxicity of essential oils is mainly connected with ROS production in the plant tissues (they observed an increase of ROS in the seedlings). The increased level of phenolics in the leaves and roots of some of the maize cultivars may suggest that the MPEO was taken by the roots in the initial growth of maize. Next, it was transported to the aboveground parts, where the ROS were generated and the plant-protective phenolics produced. However, this phenomenon would need further biochemical and physiological studies.

The second experiment showed that maize's growth, especially roots, was also inhibited in the presence of maltodextrin-a carrier of microcapsules. Moreover, in the presence of maltodextrin, high levels of phenolic compounds in the roots were observed. The effects were both substrate and cultivar dependent, and point to possible additive phytotoxicity of both peppermint oil and maltodextrin carrier against maize. This finding is supported by a similar, inhibiting effect of soil-applied maltodextrin, at doses of 50 and $100 \mathrm{~g} \mathrm{~m}^{-2}$, on development of maize and weed composition in maize cultivation, observed in a field experiment by Synowiec et al. [7].

In conclusion, the microencapsulated peppermint oil displays a dose-dependent phytotoxic effect on maize. The adverse effects, such as delayed maize emergence, and impaired development of plants occurred already at the lowest of the applied doses of MPEO, equal to $36 \mathrm{~g} \mathrm{~m}^{-2}$. The other two factors, i.e., the type of substrate and the cultivar of maize, can modify this effect, but to a limited extent. Also, maltodextrin - a carrier of microcapsules, affects maize roots' growth and increases phenolic compounds' accumulation in the root's tissues. The sorption abilities of vermiculite and clayey soil toward the microencapsulated peppermint EO and the resulting maize susceptibility should be addressed in the nearest future to understand the mechanism of action of the MPEO.

Supplementary Materials: The following are available online at http://www.mdpi.com/2073-4395/10/9/1302/s1, Table S1: The Pearson's correlation matrix for parameters studied in substrate vermiculite, Table S2: The Pearson's correlation matrix for parameters studied in the growth substrate soil 1 (above diagonal) and soil 2 (below diagonal), Table S3: Mean squares from three-way analysis of variance for eight quantitative parameters of maize, Table S4: Mean values ( \pm standard deviation) for shoot length of maize cultivars growing in the three different growth substrates amended with five doses of microencapsulated peppermint oil $\left(\mathrm{g} \mathrm{m}^{-2}\right)$ and control $\left(0 \mathrm{~g} \mathrm{~m}^{-2}\right)$, Table S5: Mean values ( \pm standard deviation) for root length of maize cultivars growing in the three different 
growth substrates amended with five doses of microencapsulated peppermint oil $\left(\mathrm{g} \mathrm{m}^{-2}\right)$ and control $\left(0 \mathrm{~g} \mathrm{~m}^{-2}\right)$, Table S6: Mean values ( \pm standard deviation) for root dry weight of maize cultivars growing in the three different growth substrates amended with five doses of microencapsulated peppermint oil $\left(\mathrm{g} \mathrm{m}^{-2}\right)$ and control $\left(0 \mathrm{~g} \mathrm{~m}^{-2}\right)$, Table S7: Mean values ( \pm standard deviation) for shoot dry weight of maize cultivars growing in the three different growth substrates amended with five doses of microencapsulated peppermint oil $\left(\mathrm{g} \mathrm{m}^{-2}\right)$ and control $\left(0 \mathrm{~g} \mathrm{~m}^{-2}\right)$, Table S8: Mean values ( \pm standard deviation) for specific leaf weight of maize cultivars growing in the three different growth substrates amended with five doses of microencapsulated peppermint oil $\left(\mathrm{g} \mathrm{m}^{-2}\right)$ and control $\left(0 \mathrm{~g} \mathrm{~m}^{-2}\right)$, Table S9: Mean values ( \pm standard deviation) for the content of phenolic compounds in the second leaf of maize cultivars growing in the three different growth substrates amended with five doses of microencapsulated peppermint oil $\left(\mathrm{g} \mathrm{m}^{-2}\right)$ and control $\left(0 \mathrm{~g} \mathrm{~m}^{-2}\right)$, Table S10: Mean values ( \pm standard deviation) for the content of phenolic compounds in the roots of maize cultivars growing in the three different growth substrates amended with five doses of microencapsulated peppermint oil $\left(\mathrm{g} \mathrm{m}^{-2}\right)$ and control $\left(0 \mathrm{~g} \mathrm{~m}^{-2}\right)$, Table S11: Correlation coefficients between the first two canonical variables and original parameters, Table S12: Mean squares from three-way analysis of variance for seven quantitative parameters of maize treated with maltodextrin only, Table S13: Mean values ( \pm standard deviation) for root length of maize cultivars growing in the three different growth substrates amended with maltodextrin $\left(\mathrm{g} \mathrm{m}^{-2}\right)$, Table S14: Mean values ( \pm standard deviation) for root dry weight of maize cultivars growing in the three different growth substrates amended with maltodextrin $\left(\mathrm{g} \mathrm{m}^{-2}\right)$, Table S15: Mean values ( \pm standard deviation) for phenolics content in roots of maize cultivars growing in the three different growth substrates amended with maltodextrin $\left(\mathrm{g} \mathrm{m}^{-2}\right)$.

Author Contributions: Conceptualization, A.S.; methodology, A.S.; investigation, A.S. and A.K.; data curation, J.B. and A.S.; writing-original draft preparation, A.S., J.B., A.K.; visualization, J.B., A.S.; funding acquisition, A.S. All authors have read and agreed to the published version of the manuscript.

Funding: This research was funded by the LeStudium/Marie Sklodowska-Curie Fellowship, grant number 665790.

Acknowledgments: Agnieszka Synowiec would like to thank E. Lainé, Director of the Research Unit at the Pôle Universitaire in Chartres, France, for providing her with space and equipment to perform the greenhouse experiments and biochemical analyses of plants.

Conflicts of Interest: The authors declare no conflict of interest. The funders had no role in the design of the study; in the collection, analyses, or interpretation of data; in the writing of the manuscript, or in the decision to publish the results.

\section{References}

1. Ibáñez, M.D.; Blázquez, M.A. Phytotoxicity of essential oils on selected weeds: Potential hazard on food crops. Plants 2018, 7, 79. [CrossRef] [PubMed]

2. Smeriglio, A.; Trombetta, D.; Cornara, L.; Valussi, M.; De Feo, V.; Caputo, L. Characterization and phytotoxicity assessment of essential oils from plant byproducts. Molecules 2019, 24, 2941. [CrossRef] [PubMed]

3. Synowiec, A.; Kalemba, D.; Drozdek, E.; Bocianowski, J. Phytotoxic potential of essential oils from temperate climate plants against the germination of selected weeds and crops. J. Pest Sci. 2017, 90, 407-419. [CrossRef]

4. Hashem, A.S.; Awadalla, S.S.; Zayed, G.M.; Maggi, F.; Benelli, G. Pimpinella anisum essential oil nanoemulsions against Tribolium castaneum-Insecticidal activity and mode of action. Environ. Sci. Pollut. Res. 2018, 25, 18802-18812. [CrossRef]

5. Dayan, F.E. Is there a natural route to the next generation of herbicides? Outlooks Pest Manag. 2018, $29,54-57$. [CrossRef]

6. Karamanoli, K.; Ainalidou, A.; Bouzoukla, F.; Vokou, D. Decomposition profiles of leaf essential oils in the soil environment. Ind. Crops Prod. 2018, 124, 397-401. [CrossRef]

7. Synowiec, A.; Lenart-Boroń, A.; Bocianowski, J.; Lepiarczyk, A.; Kalemba, D. How Soil-Applied Maltodextrin with Caraway (Carum carvi L.) Oil Affects Weed and Soil Microbiological Activity in Maize (Zea mays L.) Stands. Pol. J. Environ. Stud. 2020, 29, 817-826. [CrossRef]

8. Kalemba, D.; Synowiec, A. Agrobiological Interactions of Essential Oils of Two Menthol Mints: Mentha piperita and Mentha arvensis. Molecules 2019, 25, 59. [CrossRef]

9. Chalchat, J.-C.; Garry, R.-P.; Michet, A. Variation of the Chemical Composition of Essential Oil of Mentha piperita L. during the Growing Time. J. Essent. Oil Res. 1997, 9, 463-465. [CrossRef]

10. Sarkic, A.; Stappen, I. Essential oils and their single compounds in cosmetics-A critical review. Cosmetics 2018, 5, 11. [CrossRef] 
11. Oroian, C.; Covrig, I.; Odagiu, A.; Mălinaș, C.; Moldovan, C.; Fleșeriu, A. Effects of cultivation systems and environmental conditions on peppermint (Mentha $\times$ piperita L.) biomass yield and oil content. Notulae Bot. Horti Agrobot. Cluj Napoca 2017, 45, 576-581. [CrossRef]

12. Ostadi, A.; Javanmard, A.; Machiani, M.A.; Morshedloo, M.R.; Nouraein, M.; Rasouli, F.; Maggi, F. Effect of different fertilizer sources and harvesting time on the growth characteristics, nutrient uptakes, essential oil productivity and composition of Mentha $\times$ piperita L. Ind. Crops Prod. 2020, 148, 112290. [CrossRef]

13. Maes, C.; Bouquillon, S.; Fauconnier, M.-L. Encapsulation of Essential Oils for the Development of Biosourced Pesticides with Controlled Release: A Review. Molecules 2019, 24, 2539. [CrossRef] [PubMed]

14. Gorena, R.T.; Romero, N.; Sepulveda, E.; Chavez, J.; Saenz, C. Encapsulation of polyphenols and anthocyanins from pomegranate (Punica granatum) by spray drying. Int. J. Food Sci. Technol. 2010, 45, 1386.

15. Adamiec, J.; Kalemba, D. Analysis of microencapsulation ability of essential oils during spray drying. Drying Technol. 2006, 24, 1127-1132. [CrossRef]

16. Synowiec, A.; Smęda, A.; Adamiec, J.; Kalemba, D. The effect of microencapsulated essential oils on the initial growth of maize (Zea mays) and common weeds (Echinochloa crus-galli and Chenopodium album). Prog. Plant Prot. 2016, 56, 372-378.

17. Synowiec, A.; Możdżeń, K.; Krajewska, A.; Landi, M.; Araniti, F. Carum carvi L. essential oil: A promising candidate for botanical herbicide against Echinochloa crus-galli (L.) P. Beauv. in maize cultivation. Ind. Crops Prod. 2019, 140, 111652. [CrossRef]

18. Karkanis, A.; Alexiou, A.; Katsaros, C.; Petropoulos, S. Allelopathic Activity of Spearmint (Mentha spicata L.) and Peppermint (Mentha $\times$ piperita L.) Reduces Yield, Growth, and Photosynthetic Rate in a Succeeding Crop of Maize (Zea mays L.). Agronomy 2019, 9, 461. [CrossRef]

19. Synowiec, A.; Krajewska, A. Soil or Vermiculite-Applied Microencapsulated Peppermint Oil Effects on White Mustard Initial Growth and Performance. Plants 2020, 9, 448. [CrossRef]

20. Carlile, W.; Cattivello, C.; Zaccheo, P. Organic Growing Media: Constituents and Properties. Vadose Zone J. 2015, 14, 1-13. [CrossRef]

21. Adams, R.P. Identification of Essential Oil Components by Gas Chromatography/Mass Spectrometry, 4th ed.; Allured Publishing Corporation: Carol Stream, IL, USA, 2007.

22. Jumrani, K.; Bhatia, V.S.; Pandey, G.P. Impact of elevated temperatures on specific leaf weight, stomatal density, photosynthesis and chlorophyll fluorescence in soybean. Photosynth. Res. 2017, 131, 333-350. [CrossRef]

23. Singleton, V.L. Colorimetry of total phenolics with phosphomolybdic phosphotungstic acid reagents. Am. J. Enol. Vitic. 1965, 16, 144-158.

24. Yap, B.W.; Sim, C.H. Comparisons of various types of normality tests. J. Stat. Comput. Simulat. 2011, 81, 2141-2155. [CrossRef]

25. Rencher, A.C. Interpretation of canonical discriminant functions, canonical variates, and principal components. Am. Statist. 1992, 46, 217-225.

26. Bocianowski, J.; Majchrzak, L. Analysis of effects of cover crop and tillage method combinations on the phenotypic traits of spring wheat (Triticum aestivum L.) using multivariate methods. Appl. Ecol. Environ. Res. 2019, 17, 15267-15276. [CrossRef]

27. De Maesschalck, R.; Jouan-Rimbaud, D.; Massart, D.L. The Mahalanobis distance. Chemom. Intell. Lab. Syst. 2000, 50, 1-18. [CrossRef]

28. Seidler-Łożykowska, K.; Bocianowski, J. Evaluation of variability of morphological traits of selected caraway (Carum carvi L.) genotypes. Ind. Crops Prod. 2012, 35, 140-145. [CrossRef]

29. Camussi, A.; Ottaviano, E.; Calinski, T.; Kaczmarek, Z. Genetic distances based on quantitative traits. Genetics 1985, 111, 945-962.

30. Ritz, C.; Baty, F.; Streibig, J.C.; Gerhard, D. Dose-Response Analysis Using R. PLoS ONE 2015, 10 , e0146021. [CrossRef]

31. Council of Europe. European Pharmacopoeia 7.0; Council of Europe: Strasbourg, France, 2010.

32. Synowiec, A.; Halecki, W.; Wielgusz, K.; Byczyńska, M.; Czaplicki, S. Effect of Fatty Acid Methyl Esters on the Herbicidal Effect of Essential Oils on Corn and Weeds. Weed Technol. 2017, 31, 301-309. [CrossRef]

33. Mhlanga, B.; Chauhan, B.S.; Thierfelder, C. Weed management in maize using crop competition: A review. Crop Prot. 2016, 88, 28-36. [CrossRef] 
34. Knezevic, S.Z.; Evans, S.P.; Mainz, M. Yield penalty due to delayed weed control in corn and soybean. Crop Manag. 2003, 2, 1-7. [CrossRef]

35. Williams, M.M.; Lindquist, J.L. Influence of planting date and weed interference on sweet corn growth and development. Agron. J. 2007, 99, 1066-1072. [CrossRef]

36. Tursun, N.; Datta, A.; Sakinmaz, M.S.; Kantarci, Z.; Knezevic, S.Z.; Chauhan, B.S. The critical period for weed control in three corn (Zea mays L.) types. Crop Prot. 2016, 90, 59-65. [CrossRef]

37. Barros, R.E.; Faria, R.M.; Tuffi Santos, L.D.; Azevedo, A.M.; Governici, J.L. Physiological Response of Maize and Weeds in Coexistence. Planta Daninha 2017, 35, 1-8. [CrossRef]

38. Rama, M.; Laiho, T.; Eklund, O.; Wärnå, J. An evaluation of the capability of nanomodified vermiculite to in situ ammonium removal from landfill leachate. Environ. Technol. Innovat. 2019, 14, 100340. [CrossRef]

39. Tsuda, S.; Miyamoto, N.; Takahashi, H.; Ishihara, K.; Hirasawa, T. Roots of Pisum sativum L. exhibit hydrotropism in response to a water potential gradient in vermiculite. Ann. Bot. 2003, 92, 767-770. [CrossRef]

40. Gairola, K.C.; Nautiyal, A.R.; Dwivedi, A.K. Effect of temperatures and germination media on seed germination of Jatropha curcas Linn. Adv. Biores. 2011, 2, 66-71.

41. Drury, C.F.; Tan, C.S.; Welacky, T.W.; Oloya, T.O.; Hamill, A.S.; Weaver, S.E. Red clover and tillage influence on soil temperature, water content, and corn emergence. Agron. J. 1999, 91, 101-108. [CrossRef]

42. Seebauer, J.R.; Below, F.E. Use of in vitro kernel culture to study maize nitrogen and carbohydrate metabolism. In Maize; Humana Press: New York, NY, USA, 2018; pp. 3-13.

43. Kısa, D.; Elmastaş, M.; Öztürk, L.; Kayır, Ö. Responses of the phenolic compounds of Zea mays under heavy metal stress. Appl. Biol. Chem. 2016, 59, 813-820. [CrossRef]

44. Malčovská, S.M.; Dučaiová, Z.; Maslaňáková, I.; Bačkor, M. Effect of silicon on growth, photosynthesis, oxidative status and phenolic compounds of maize (Zea mays L.) grown in cadmium excess. Water Air Soil Pollut. 2014, 225, 2056. [CrossRef]

45. Sakihama, Y.; Cohen, M.F.; Grace, S.C.; Yamasaki, H. Plant phenolic antioxidant and prooxidant activities: Phenolics-induced oxidative damage mediated by metals in plants. Toxicology 2002, 177, 67-80. [CrossRef]

46. Singh, H.P.; Kaur, S.; Mittal, S.; Batish, D.R.; Kohli, R.K. Essential oil of Artemisia scoparia inhibits plant growth by generating reactive oxygen species and causing oxidative damage. J. Chem. Ecol. 2009, 35, 154-162. [CrossRef] [PubMed]

(C) 2020 by the authors. Licensee MDPI, Basel, Switzerland. This article is an open access article distributed under the terms and conditions of the Creative Commons Attribution (CC BY) license (http://creativecommons.org/licenses/by/4.0/). 